\title{
ARTICLE
}

\section{Ethnic Ties, Organized Opposition and Voter Defection in Authoritarian Elections}

\author{
Chao-Yo Cheng ${ }^{1}$ and Yi-Tzu Lin ${ }^{2}$ \\ ${ }^{1}$ Department of International Development and Department of Methodology, London School of \\ Economics and Political Science, London, UK and ${ }^{2}$ Department of Political Science, Tunghai \\ University, Taichung, Taiwan
}

*Corresponding author. Email: c.cheng23@1se.ac.uk

\begin{abstract}
Existing studies of ethnic voting mainly focus on democratic elections. In electoral autocracies, politically subordinate ethnicity can help citizens coordinate against the incumbent. However, we argue that collective action will be constrained when the group grows large, as it becomes costly for its members to form common behavioural norms and carry out effective sanctions through shared ethnic ties under authoritarian repression. Drawing on unique historical surveys in Taiwan, we study how Taiwanese ethnicity and local ethnic demography jointly induced voters' defection against the hegemonic KMT regime. We find that the pro-defection or anti-incumbent effect of Taiwanese ethnicity fell as the share of Taiwanese citizens in a township increased. However, the relative size of the Taiwanese group no longer undermined pro-defection ethnic voting after the KMT lifted the ban on opposition parties. Our results illustrate that formal organizations play a critical role in sustaining the informational salience of ethnicity in the elections.
\end{abstract}


Keywords: Taiwan; ethnic voting; non-democratic elections; political parties; democratization

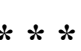

Ethnic voting in democratic elections has attracted considerable attention. Ethnicity can signal candidate quality, as well as the policy mandate of political parties, thus shaping vote choices and informing politicians' strategic moves in the elections (Ferree, 2006; Birnir, 2007). By providing eligible individuals with a shared set of behavioural norms and sanction mechanisms against within-group defection, ethnicity can act as useful information heuristics for decisionmaking while sustaining collective action (Hale, 2008).

Drawing on recent studies (Eifert et al., 2010; Adida et al., 2017), we explore how ethnicity paves the foundation of popular resistance against the incumbent ruler in multi-group electoral autocracies, as well as the conditions under which ethnicity becomes politically salient. When ethnic divisions coincide with the power asymmetry between the dictator and his subjects, shared ethnic ties can help citizens and opposition forces from the politically dominated group coordinate against the autocratic incumbent in partially competitive elections. Since nondemocratic rulers usually impose extensive restrictions on civil liberties, citizens under authoritarian rule can usually only rely on shared ethnicity for decision-making and social interactions.

Nonetheless, we contend that the visibility of group differences alone cannot sustain the salience of ethnicity for collective resistance. More specifically, we argue that the efficiency of an ethnicity as an information shortcut is likely to decline as its relative size grows large in the local community. As a group's relative size increases, individuals are less likely to note 
intergroup distinction and are more likely to resort to other attributes for decision-making. While this issue can be present in both democratic and authoritarian regimes, we posit that politically dominated ethnic groups face an even more acute challenge in this regard. These groups are likely to be the target of autocratic repression that seeks to undermine any potential group-based mobilization that can take place either through traditional social groups or modern political organizations.

As a result, we argue that ethnicity in authoritarian regimes can best act as an informal device for individuals' spontaneous actions that allow individuals to defy the dictator's rule as a group. Without effective organizational support, the mobilizing capacity of ethnicity is prone to the common pitfalls of effective collective action in large groups (Olson, 1965). While ethnicity can be considered as an 'institution' by providing individuals with the foundation of social order and informs differences in preferences, information and beliefs for interpersonal transactions and group-based political endeavours, ethnicity will cease to serve as an effective coordination and sanction device in large groups as it is hard to secure the agreed sets of shared "preferences, information, and beliefs" in an informal setting.

We focus on the case of post-war Taiwan. In 1949, as the Chinese Communist Party (CCP) of claimed its victory in the Chinese Civil War, Chiang Kai-shek relocated his Kuomintang (KMT) government to Taiwan and introduced martial law. In the next four decades, the KMT government imposed various restrictions on press freedom and civil liberties in Taiwan. The KMT's hegemonic rule also led to the political dominance of the Mainlanders who resettled in Taiwan from mainland China following Japanese colonial rule (1895-1945) over the Taiwanese, who are largely the descendants of the Han migrants in the late 19th century. ${ }^{1}$ In 1969, the KMT called for the legislative by-election for the Legislative Yuan, the 
nominal national legislature, for the first time since 1948. The by-elections offered local Taiwanese elites a political platform at the national level to challenge the hegemonic regime. Despite the obstacles imposed by the KMT, Taiwanese politicians managed to establish various associations that led to the creation of the Democratic Progressive Party (DPP) in 1986. In 1992, nearly four decades after the 1949 relocation, the KMT government held the first multiparty election.

We analyse two unique historical surveys that document the vote choices of more than 1,000 Taiwanese citizens in the 1983 and 1992 legislative elections. The survey for the 1983 election was the first to construct a representative sample of the entire voting population. The survey was also important because it focused on the last single-party national election before the KMT lifted martial law in 1987. In brief, while Taiwanese ethnicity is positively associated with voters' defection against the KMT, we find such pro-defection or anti-incumbent effect declines as the Taiwanese proportion of a township's local population increased. Furthermore, the antiautocrat effect of Taiwanese ethnicity is no longer associated with the relative size of Taiwanese group in a township in the 1992 election, suggesting that ethnicity can overcome the collective action dilemma as the opposition managed to build a formal organization.

Our article combines the literatures on ethnic voting and electoral authoritarianism. Responding to the call for more research on voting behaviour in non-democratic elections (Gandhi and Lust-Okar, 2009), we show ethnicity can induce voter defection against the incumbent in an environment with highly restricted information. Furthermore, by showing how the anti-incumbent effect of a politically dominated ethnicity can be constrained by local ethnic demography, we demonstrate that without a solid organizational foundation, ethnicity could only trigger voter defection at a much smaller scale in a spontaneous manner. Our findings, in this 
vein, may seem counterintuitive for those familiar with the literature on ethnic politics in democracies (e.g., Posner 2004), as we have shown how relative group size can undermine ethnic mobilization. Finally, our study extends the literature on the politics of post-war Taiwan. While existing studies mostly focus on elections after the democratic transition (Wu and Hsiao, 2006; Cheng, 2009), we trace the root of ethnic voting among Taiwanese voters as the means to combat hegemonic rule back to the martial law period.

\section{Pro-Defection Ethnic Voting in Authoritarian Elections}

In this section, we present our theoretical argument and testable implications. We start by highlighting that ethnicity can act as a crucial information shortcut permitting cooperation and coordination within politically dominated groups in both democratic and authoritarian elections. We then explain how relative group size can undermine the efficiency of shared ethnic ties for collective action and why relative group size is more likely to constrain the mobilization of subordinate groups in ethnically diverse authoritarian regimes.

To begin with, existing studies of ethnic voting have mostly focused on democratic elections dictated by ethnic divisions (Ferree, 2006; Birnir, 2007; Horowitz and Long, 2016; Adida et al., 2017). Ethnicity allows individuals of the same ethnicity to coordinate their beliefs about the strategy set and chosen actions of each other. In elections, ethnicity thus signals not only candidate quality but also the policy mandate of different parties, both of which in turn shape voters' choices while informing politicians of their political alignment and campaign strategies.

As in democratic countries, we argue that ethnic cleavages can signal shared desirable goals among individuals of the same ethnicity in autocracies. Ethnicity establishes the expected 
norms of interactions among co-ethnic individuals, as well as between individuals from different groups, setting the boundary of conformity and sanctioning deviations. With various restrictions on civil liberties, autocrats seek to control the flow of information and ideas, putting citizens in an opaque information environment. In doing so, the autocrat gains the leverage to increase the cost of anti-regime mobilization as he isolates his subjects from each other. When ethnic cleavages coincide with the power asymmetry between the dictator and his subjects, the latter can resort to co-ethnic ties to assess the viability of different political actions and collaborate to defend their group interests. Although dictators often curtail or even repress the salience of ethnic divisions, ethnically based mobilization has sustained popular struggle against dictatorships or played a crucial role in driving democratic transitions. In the former Soviet Union, ethnicity also facilitated electoral mobilization and mass protests that led to regime transition in the 1980s (Roeder, 1991; Beissinger, 2002; Finkel, 2015).

However, the political salience of ethnicity is conditional. Since ethnicity is a multidimensional social construct encompassing various identity 'categories', such as religion, language, place of origin and tribal affiliation, researchers have developed two avenues of research. As individuals possess their own 'identity repertoire' (Posner, 2017), which includes a broad range of identity attributes, it remains to be answered whether a particular attribute or a subset of it provides the basis of decision-making and collective action under different political and socioeconomic contexts. The literature on constitutional design highlights the impact of institutions on politicizing social cleavages and exacerbating existing conflicts (Cederman et al., 2010; Eifert et al., 2010). Others explore economic factors of intergroup perceptions and groupbased mobilization (Cederman et al., 2011; Huber and Suryanarayankas, 2016). Finally, studies of civil wars show how local ethnic demography can influence the political relevance of group 
divisions. For instance, Kimuli Kasara (2017) shows that segregation will create a security dilemma between different groups by hindering inter-group communication and increasing distrust.

Focusing on a single case (post-war Taiwan), we have held the institutional context constant. Doing so also allows us to treat the economic relations as given -- the divide between the Taiwanese and Mainlanders coincided with the economic gap between these two ethnic blocs (Gates 1981; Yang 2011). In line with the last research avenue, we posit that community-level ethnic composition plays a crucial role in shaping individuals' informational consideration related to their ethnicity. We propose that the political salience will decline as the relative group size grows. First, as the number of individuals that can fall into a particular ethnicity increases, individuals will have to consider more potential variation when formulating and processing the norms and expectations shared among their co-ethnic members, requiring greater effort to maintain group boundaries. Citizens in dictatorships will face more difficulty because dictators impose strict surveillance to inhibit coordination among their subjects. Second, individuals' share of symbolic and material utilities tied to ethnicity will be diluted as the group's relative size increases, rendering co-ethnic ties less attractive as a shortcut for information processing and decision-making (Posner, 2017). Third, when a single group accounts for the majority in the community, it will also be more difficult for individuals to formulate their understandings of group contrast as they are less likely to encounter those from other groups. Under such circumstances, individuals will have the incentive to resort to other heuristics or even establish subgroups under a given ethnicity. Mancur Olson (1965) compares the dynamics of collective action in large and small groups. Compared to small groups, large groups require additional inducement or measures, which are often coercive and formal, to enforce individuals' 
contribution to the production of collective goods. Large groups, meanwhile, often face a greater cost of coordination than small groups do and thus suffer from the under-supply of public goods.

While the same constraint is present regardless of regime types, we argue that politically dominated groups under authoritarian rule are more likely to suffer than those in democracies. Collective action in a large group often requires a formal organization to settle any internal disagreements. Since civic organizations, including those based on ethnicity, are subject to either crackdown or extensive scrutiny in authoritarian regimes, ethnicity can only serve as an informal institution that signals the package of shared norms and behaviour expectations. While informal institutions, like their formal counterparts, help to reduce the challenge of information asymmetry and transaction costs between individuals and facilitate collective action, they lack credible enforcement mechanisms. Decision-making based on ethnicity in autocracies involves an extra hurdle on individuals to account for potential defections and a large margin of errors by themselves.

As a result, in an authoritarian regime, the capacity of ethnicity as the driving force of collective resistance, such as voting for opposition candidates in authoritarian elections, is limited. While ethnicity can induce coordination and mobilize voters from the same group, ethnically based resistance can be subject to the usual pitfalls of collective action in large groups. In contrast, democratic political parties tackle the weakness of ethnicity as an institution of collective action. A political party can be more efficient than informal group associations to aggregate different preferences and interests with formal membership and grassroots organizations (Panebianco, 1988). First, the formal membership provides a credible public signal by incorporating ethnicity to inform actors, including both politicians and voters, of mutually acceptable political objectives and a credible sanction platform to induce long-term commitment 
against deviations. Next, compared with informal associations, political parties can also develop or connect existing local apparatus to coordinate politicians and reach out to voters across different constituencies under a single brand (Cox and McCubbins, 1993; Aldrich, 1995). Existing studies have also shown the importance of political parties in sustaining identity-based political mobilization. In India, Kanchan Chandra (2004) and others have studied how ethnic parties can mobilize the votes of lower caste communities and other historically marginalized social groups. Dawn Brancati (2009) argues that the presence of regional parties determines whether decentralization will encourage secession movements and endanger state integrity. In both cases, political parties provide a domain that bolsters the institutional value of ethnicity for credible transactions between individuals.

To sum up, while ethnicity helps to facilitate and sustain resistance against the autocratic incumbent among the politically dominated group, we argue that its efficiency can be constrained by local ethnic demography. In other words, the political salience or relevance of ethnicity depends on not only the visibility of ethnic differences but also the presence of formal organizational support. $^{2}$

Empirically, Taiwanese ethnicity should help the subordinate Taiwanese voters overcome the information disadvantage imposed by the hegemonic rule and spontaneously coordinate their defection, although the pro-defection or anti-incumbent effect of Taiwanese ethnic is limited. We expect the relative group size would no longer serve as the constraint on anti-incumbent ethnic voting after the KMT government lifted martial law. That is, compared with the 1983 election, the relative group size should not undermine the pro-opposition effect of Taiwanese ethnicity in the 1992 multiparty election. 
Hypothesis 1. Taiwanese voters are more likely to defect against the autocratic incumbent in authoritarian elections.

Hypothesis 2. The pro-defection effect of Taiwanese ethnicity decreases as the relative size of the Taiwanese group in the local community increases.

Hypothesis 3. The relative group size in the local community does not undermine the prodefection effect of Taiwanese ethnicity with the presence of an opposition party.

\section{National Legislative Elections in Post-War Taiwan}

In 1949, as the CCP seized control over mainland China, Chiang Kai-shek relocated the KMT government to Taiwan and introduced martial law to hold out against the CCP. Martial law granted Chiang and the KMT supreme authority above the democratic constitution. In the absence of effective checks and balance, the KMT regime imposed extensive restrictions on civil rights in Taiwan. Soon afterwards, Chiang suspended all national elections and banned the formation of new political parties.

As a result, the Legislative Yuan - the national legislative body - became the 'rubber stamp' of the hegemonic KMT regime (Copper and Chen, 1984). It was not until 1969 that the KMT announced the plan to organize the first 'supplementary' election for the national parliament. Previous research has offered two reasons behind Chiang's decision to hold the election. First, the KMT wanted to fill the seats vacated by the deaths of elderly legislators, most of whom were elected in mainland China. ${ }^{3}$ Since only a subset of seats was open for contestation, the proposed legislative election was essentially a by-election. Secondly, broadly 
speaking, the KMT in the 1960s faced a series of diplomatic setbacks that jeopardized Chiang's leverage to represent himself as the leader of the only legitimate "democratic" China in the world (Chao, 1996). ${ }^{4}$ Chiang sought to distinguish his Taiwan-based KMT regime from the CCP in the Mainland by holding a national election. Following the 1969 election, the KMT continued to hold supplementary elections every three years.

Like other electoral autocracies, the KMT also attempted to constrain the presence of non-KMT candidates through various means. For instance, non-KMT candidates were often arbitrarily removed from the elections. As in local elections, the KMT also engaged in clientelistic vote buying and election fraud (Wang, 1997). More crucially, given that the formation of new political parties remained outlawed, non-KMT politicians could only contest as independent candidates. Meanwhile, these elections adopted the single non-transferable voting (SNTV) system, which is known for providing a relatively lower winning threshold than the plurality system (Lijphart, 1999). With a greater chance of winning a seat in multi-member districts, the SNTV system created an additional barrier for the opposition to organize and coordinate (Cheng, 1989).

Despite all the obstacles, the KMT's decision to hold the supplementary elections was still a critical watershed. For one thing, these elections, although rigged, offered Taiwanese politicians a platform to partake in politics at the national level. By the late 1970s, they managed to join together to voice their discontent against Chiang and his hegemonic KMT regime, as well as the disproportionate dominance of the Mainlanders, who only accounted for the minority of the total population. ${ }^{5}$ With Mainlanders taking most leading government posts, non-KMT politicians began to incorporate the pursuit of ethnic empowerment into their request for democracy (Hsieh, 2003). 
In the late 1970s, non-KMT politicians began to create pre-electoral alliances to coordinate candidate nominations and campaign strategies among themselves (Huang, 1992). While these alliances were mostly temporary, in September 1983, several non-KMT politicians created a writers' association, 'tangwai' (meaning 'outside the party', namely the KMT), in Taipei Municipality. While John Copper and George Chen (1984) consider tangwai as a political party, it is important to note that non-KMT politicians could only coordinate as independent candidates in the elections. Moreover, they were not able to recruit formal party members to build efficient mobilization machines at the grassroots level. Three years later, defying the KMT's ban on new parties, tangwai politicians announced the formation of the Democratic Progressive Party (DPP) in September 1986 to officially contest the KMT's hegemonic rule in Taiwan. In the end, the KMT government did not take any action against the DPP and suspended martial law the following year. ${ }^{6}$ In 1992, the KMT government held the first multiparty legislative election since 1948. As shown in Figure 1, the presence of non-KMT legislators in the Legislative Yuan remained limited throughout the martial law period; that said, the number of seats open for contestation slightly increased. 


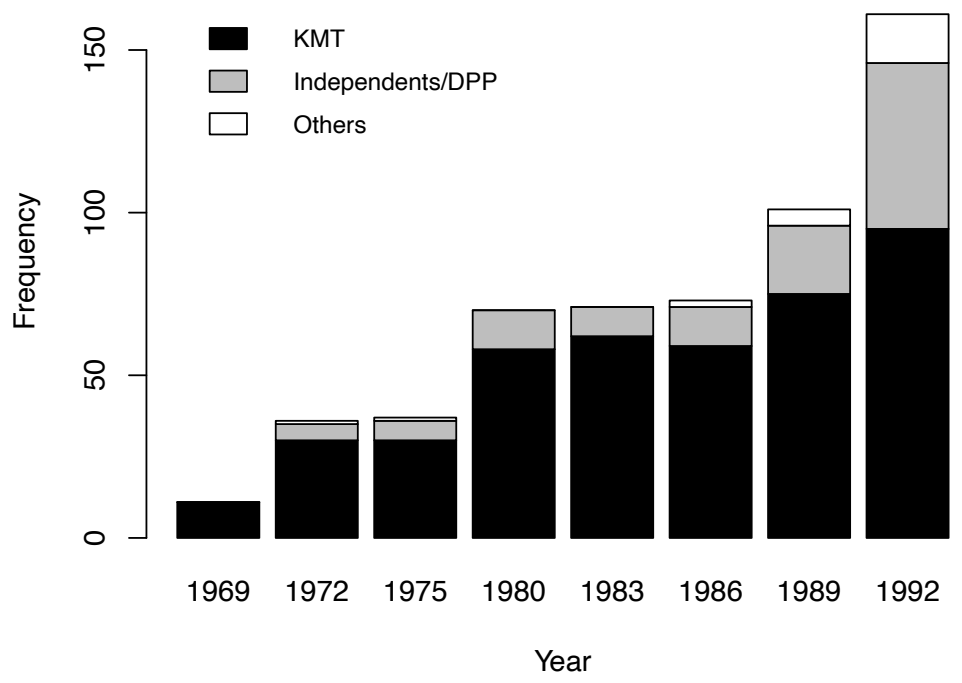

Figure 1: Party composition of elected Legislative Yuan members, 1969-1992.

\section{Empirical Analysis}

Our analysis draws on two unique surveys conducted by researchers from the National Taiwan University (NTU) following the 1983 and 1992 elections (hereafter '1983 survey' and '1992 survey'). The 1983 survey was the very first one that sought to study the citizens' vote choices under martial law, based on a representative sample in Taiwan. The NTU researchers collected more than 1,000 responses from six counties, each of which was randomly selected from a constituency. Two townships were then randomly chosen from each county.

The 1992 survey includes similar questions to the 1983 survey, thus providing us with the opportunity to compare voters' preferences (or intentions) before and after the lifting of martial law. Following a similar sampling scheme, the NTU team created the study sample from ten counties. It is important to stress that the sample is representative only with respect to the voting population in the election. The changes in the number of sampled counties reflected the results of 
redistricting in the 1992 election. ${ }^{7}$ Figure A1 in the Online Appendix shows the locations of sampled townships in each survey.

In the following analysis, we have decided to exclude all responses from Taipei Municipality because the 1983 survey did not specify the districts (as it did for townships in the counties) from which the sample was collected. ${ }^{8}$ Later, we will include responses from Taipei Municipality in one of our robustness checks and discuss how our results are influenced by their inclusion in the analysis. We present the summary statistics of our main variables in the Online Appendix (Tables A1 and A2).

\section{Explanatory Variable}

The explanatory variable is a binary indicator that takes the value of 1 if a respondent is of Taiwanese ethnicity, which refers to the descendants of the Han people who migrated from mainland China before Japanese colonial rule (1895-1945). ${ }^{9}$ To be specific, Taiwanese ethnicity includes two groups: Hoklo and Hakka, both of which could trace their ancestors back to Fujian and Guangdong in the Mainland. In addition to these two groups, one can also find indigenous peoples in Taiwan. According to existing archaeological evidence, these peoples had moved to Taiwan from different Pacific islands long before the Han Chinese's arrival in the 17th century. Finally, Mainlanders refers to the Han Chinese migrants that arrived in Taiwan after WWII, as well as their descendants. Figure A3 in the Online Appendix shows the ethnic composition of the study sample in each survey.

Under the KMT's hegemonic rule, Hoklo and Hakka were both politically dominated by the Mainlanders. In line with previous studies, we have decided to focus on the Hoklo people, who were relatively outspoken against the KMT regime, in the following analysis (Sheng, 1986). 
For one thing, while the Hakka people have maintained a unique group identity, it was not until the post-martial law era that they became politically active (Wang, 2005). Also, the Hoklo group accounts for a greater portion among the local Taiwanese than the Hakka group. Since the surveys adopted multilevel sampling to create representative samples, they only included a small number of Hakka and indigenous respondents. ${ }^{10}$ The robustness test shows that our findings do not depend on the decision to exclude these groups.

All survey respondents were asked to provide the ethnicity of their parents. Again, following previous studies, we define each respondent's ethnicity based on the father's ethnicity (Sheng, 1986). In other words, a respondent is considered of Taiwanese ethnicity if his or her father is of the same ethnicity. Nevertheless, we recode our variable by defining respondents as Taiwanese only if both of their parents are Taiwanese. Since more than 90 per cent of respondents in the surveys were raised by parents of the same ethnicity, the results are virtually identical.

\section{Dependent Variable}

Using each respondent's claimed vote choice, we create a binary indicator that takes the value of 1 if respondents declared that they did not vote for the KMT in the elections. In other words, the dependent variable indicates whether a voter is willing to express openly their disobedience.

To recap, in 1983, all non-KMT politicians had to contest as independent candidates unless they were nominated by the Young China Party (YCP) and the China Democratic Socialist Party (CDSP), both of which were created in the Mainland before 1949 and became symbolic opposition forces following the introduction of martial law. ${ }^{11}$ In the 1983 survey, nearly ten per cent of the study population reported that they did not vote. Among those who 
voted, about a fifth did not share their voting decisions. About 200 respondents reported that they voted for opposition candidates. No one indicated that they voted for the YCP or CDSP. In the 1992 survey, about 13 per cent of the study population reported that they did not vote. Among those who voted (about 1,200 participants), about 200 respondents either declined to report their vote choices or could not recall the candidates they supported. 262 and 640 respondents reported that they voted for the DPP and KMT, respectively. Figure A2 in the Online Appendix shows the vote choices of survey respondents. Figure 2 shows the survey respondents' choices by ethnicity, and Taiwanese voters were consistently more likely to defect than Mainlanders. For instance, for the 1983 election, more than 50 per cent of Taiwanese respondents declined to support the KMT, whereas only about 20 per cent of the Mainlanders did so.

Before we proceed, a caveat is warranted. As in other studies of electoral authoritarian regimes, one may question whether the survey can validly capture the voters' preferences, as the citizens were likely to conceal their true preferences. For the reason we have just highlighted, we have thus decided to focus on voter defection rather than the support for the opposition. The outcome variable of interest acts to indicate a relatively extreme case such that a respondent was willing to turn his or her back on the hegemonic party. Nonetheless, to be noted, Chiang Chingkuo, who succeeded his father Chiang Kai-shek in 1975, introduced a series of reforms to increase political participation and contestation in the 1980s. The risks involved in voting for the opposition or declining to support the KMT thus had decreased significantly compared with the 1970s. 


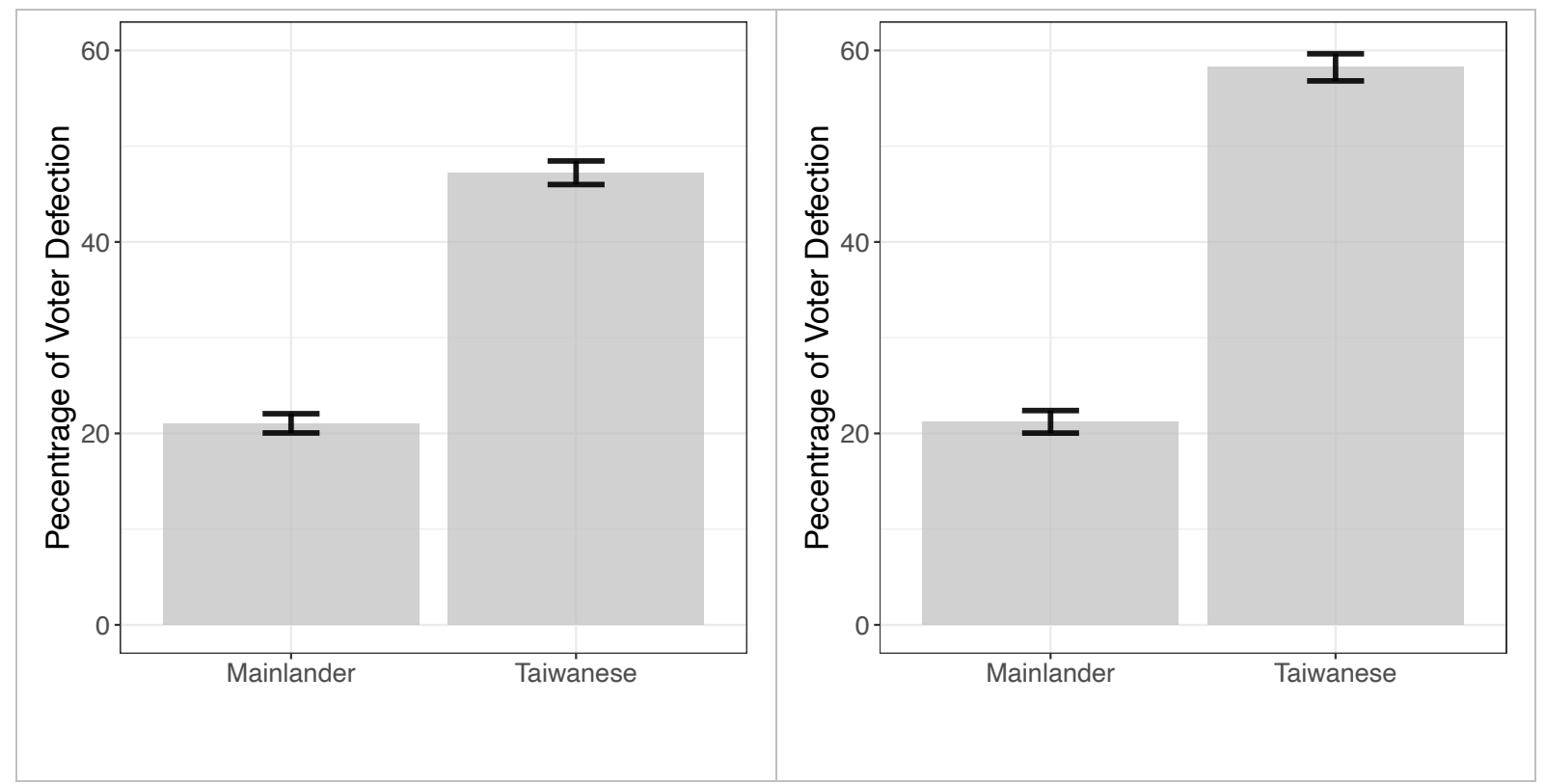

Figure 2: Voter defection by ethnicity: 1983 Survey (left) and 1992 Survey (right).

\section{Ethnic Demography}

We include the Taiwanese group's share in the population of each sampled township to test how local ethnic demography can moderate the pro-defection effect of Taiwanese ethnicity. As hypothesized, since Chiang and the KMT outlawed the formation of opposition parties, large group size can undermine the efficiency of ethnicity as an informal institution of collective action. For the 1983 election, we use the last available official data on ethnic composition from the 1980 census. For the 1992 election, we use the 1990 census data.

\section{Control Variables}

We have considered other factors that can also explain individual respondents' claimed vote choices. First, previous studies on non-democratic countries have highlighted the importance of censored media in driving subjects' approval towards or grievances against the regime (Geddes and Zaller, 1989). We thus consider each respondent's media consumption. In the early 1980s, 
mass media in Taiwan remained strictly censored. It is likely that frequent media consumption will induce individuals' support towards candidates from the hegemonic party or deter voters from expressing their support for the opposition. Both surveys included a set of questions that indicated how often each respondent watches television, listens to the radio, and reads newspapers. We recode respondents as 1 (otherwise 0) if they answered 'usually,' which was the highest among all possible ordinal options. We include each respondent's educational background. The surveys asked each respondent to report their highest level of education from nine categories, ranging from 'illiterate' to 'post-graduate.' We create an ordinal variable with higher values indicating more education a respondent received. ${ }^{12}$

We also control for two variables that indicate individuals' ties with the hegemonic regime. First, we include a binary variable that becomes 1 if a respondent was a KMT member. Being a KMT member is perhaps the most clear-cut indicator to suggest whether an individual was co-opted by the hegemonic party, thus having the incentive to support its candidates. In the sample of the 1983 survey, around a quarter of respondents were reported to be official KMT members. In the sample for the 1992 election, the percentage of KMT members fell to about $20 \%$. Second, we control for whether a respondent was a public employee, which included all respondents that chose 'military,' 'government staff' and 'teachers for primary and secondary schools' as their occupations. In hegemonic party regimes (Magaloni, 2006), citizens in these occupations are usually the dominant party's core supporters, with the various symbolic and materials benefits to the jobs in the public sector. In both surveys, public employees account for about ten per cent of the study population.

Moreover, we include three demographic and socioeconomic variables that can influence individuals' attitudes toward the KMT regime. First, we include a dummy variable to indicate 
male respondents. We also control for each respondent's age, which was measured by nine ordinal categories in the survey. We then control for household income, which ranges from 1 to 4 with the value of 4 indicating the richest households.

\section{Conditional Pro-Defection Effect of Taiwanese Ethnicity}

In Table 1, we present our main findings based on the linear probability model. ${ }^{13}$ In Section A4 in the Online Appendix we explain our model choice and specification. The first four models are based on the 1983 survey. The remaining four models are based on the 1992 survey. We first include Taiwanese ethnicity, add its interaction with the share of Taiwanese group in the township, and then include all control variables. ${ }^{14}$ In addition to the explanatory and control variables, we have also included county fixed effects in the analysis to account for various location-specific factors, such as the degree of urbanization -- some suggest that rural voters are most prone to the KMT's clientelistic mobilization (Wu, 1987), the number of competing local political factions, the number of candidates in the elections, and the ethnic composition of candidates. ${ }^{15}$ 
Table 1: Estimates of voter defection.

\begin{tabular}{|c|c|c|c|c|c|c|c|c|}
\hline & \multicolumn{4}{|c|}{1983 election } & \multicolumn{4}{|c|}{1992 election } \\
\hline & (1) & (2) & (3) & (4) & (5) & (6) & (7) & (8) \\
\hline \multirow[t]{2}{*}{ Taiwanese $(=1)$} & $0.255^{* * *}$ & $0.224 * * *$ & $0.104 * *$ & $0.071^{*}$ & $0.286^{* * *}$ & $0.248 * * *$ & $0.212 * * *$ & $0.189^{* * *}$ \\
\hline & $(0.054)$ & $(0.049)$ & $(0.044)$ & $(0.041)$ & $(0.048)$ & $(0.059)$ & $(0.050)$ & $(0.057)$ \\
\hline \multirow[t]{2}{*}{ Share of Taiwanese group } & & $0.038^{*}$ & & 0.031 & & 0.048 & & 0.024 \\
\hline & & $(0.021)$ & & $(0.021)$ & & $(0.030)$ & & $(0.028)$ \\
\hline \multirow[t]{2}{*}{ Taiwanese $\mathrm{x}$ Share of Taiwanese } & & $-0.074 * * *$ & & $-0.079 * * *$ & & -0.052 & & -0.036 \\
\hline & & $(0.023)$ & & $(0.020)$ & & $(0.037)$ & & $(0.034)$ \\
\hline \multirow[t]{2}{*}{ Media use (= 1) } & & & $-0.170 * * *$ & $-0.169 * * *$ & & & $-0.109 * *$ & $-0.107 * *$ \\
\hline & & & $(0.041)$ & $(0.040)$ & & & $(0.043)$ & $(0.043)$ \\
\hline \multirow[t]{2}{*}{ Education } & & & -0.015 & -0.016 & & & -0.003 & -0.004 \\
\hline & & & $(0.011)$ & $(0.012)$ & & & $(0.013)$ & $(0.013)$ \\
\hline \multirow[t]{2}{*}{ KMT member $(=1)$} & & & $-0.207 * * *$ & $-0.206 * * *$ & & & $-0.213 * * *$ & $-0.212 * * *$ \\
\hline & & & $(0.041)$ & $(0.039)$ & & & $(0.041)$ & $(0.042)$ \\
\hline \multirow[t]{2}{*}{ Public employee $(=1)$} & & & 0.035 & 0.038 & & & -0.004 & -0.004 \\
\hline & & & $(0.082)$ & $(0.081)$ & & & $(0.037)$ & $(0.036)$ \\
\hline \multirow[t]{2}{*}{ Household income } & & & $-0.050 * *$ & $-0.048 * *$ & & & -0.016 & -0.015 \\
\hline & & & $(0.023)$ & $(0.022)$ & & & $(0.022)$ & $(0.022)$ \\
\hline \multirow[t]{2}{*}{ Age } & & & $-0.020 * *$ & $-0.020 * *$ & & & -0.011 & -0.011 \\
\hline & & & $(0.008)$ & $(0.008)$ & & & $(0.007)$ & $(0.007)$ \\
\hline \multirow[t]{2}{*}{ Male (= 1) } & & & $0.090 * * *$ & $0.092 * * *$ & & & $0.088^{* * *}$ & $0.088^{* * *}$ \\
\hline & & & $(0.021)$ & $(0.021)$ & & & $(0.031)$ & $(0.031)$ \\
\hline Observations & 1,392 & 1,392 & 1,335 & 1,335 & 1,003 & 1,003 & 1,001 & 1,001 \\
\hline Adjusted $\mathrm{R}^{2}$ & 0.031 & 0.032 & 0.097 & 0.099 & 0.068 & 0.068 & 0.106 & 0.105 \\
\hline
\end{tabular}

For both elections, the Taiwanese coefficients are constantly positive and statistically significant. In other words, before and after the lifting of martial law, Taiwanese ethnicity is associated with voters' defection against the hegemonic party. Compared with their 1983 counterparts, the estimated marginal coefficients of Taiwanese ethnicity are greater in the case of the 1992 election. This finding aligns with our conjecture that highlights the importance of formal political organization in bolstering the anti-autocrat effect of Taiwanese ethnicity. In the same table, the estimated coefficients of the interaction term are negative for both elections, 
suggesting that the pro-defection effect of Taiwanese ethnicity declines as the relative size of the Taiwanese group grew large in the township. However, they are only statistically significant for the 1983 election.

Overall, we observe a consistent anti-incumbent effect of Taiwanese ethnicity in both elections. Nevertheless, its pro-defection effect has appeared to be undermined by the relative group size under the KMT's hegemonic rule, as we have proposed above. Following the lifting of the ban on opposition parties, we find that the relative group size no longer serves as a constraint. Figure 3 shows the estimated effect of Taiwanese ethnicity, conditional on the share of the Taiwanese group in the township. Only in the 1983 survey did the pro-defection impact of Taiwanese ethnicity decline as the share of Taiwanese in the township grew.

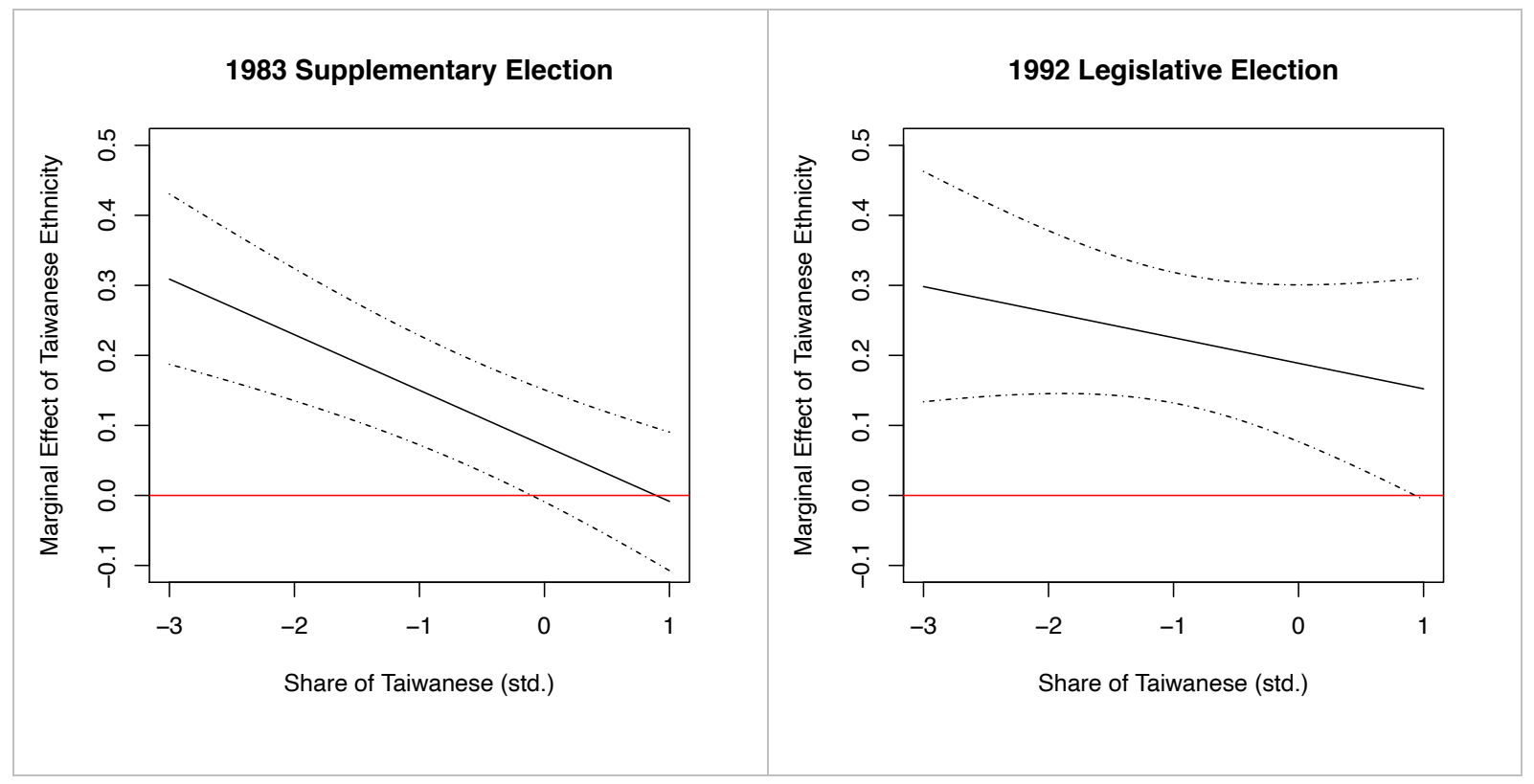

Figure 3: Conditional anti-incumbent effect of Taiwanese ethnicity: 1983 Survey and 1992 Survey. Error bars show the 95\% confidence intervals. 
We conduct several tests to evaluate the robustness of our main findings (Section A5 in the Online Appendix). Two tests are worth particular attention. First, when we include Taipei Municipality, the interaction term's estimated coefficient for the 1983 election is no longer statistically significant. In addition to the data constraint mentioned above, this result is in fact consistent without overall argument, as Taipei Municipality was the only place where non-KMT politicians coordinated to create an organized alliance prior to the 1983 election. Second, one of the robustness tests considers the nonlinear effect of local ethnic demography, and the estimated coefficient of the squared Share of Taiwanese is statistically insignificant. This result is consistent with our argument that the visibility of group differences alone does not sustain the political salience of ethnic ties.

Our control variables also exhibit interesting patterns. For both elections, Media use is negatively correlated with voter defection, although the size of estimated coefficients decreased for the 1992 election. The estimated coefficients of Media use may suggest that the lasting and yet decreasing impact of media censorship imposed by the hegemonic party. Next, being a KMT member is negatively correlated with voter defection, perhaps unsurprisingly. Finally, we find that male voters were more likely to defect from supporting the KMT in the 1983 election under the Martial Law. ${ }^{16}$

Next, we consider the correlates of non-responses. In many democratic and authoritarian elections, voters often express their grievances against the incumbent implicitly by declining to express their opinions (Shi, 1999; Cohen, 2018). We also explore the correlates of negative attitudes towards the quality of elections. The dependent variables are two binary indicators that take the value of 1 if the respondent did not vote (or declined to report their vote choices) and 
perceived elections as fraught with rigging, respectively. We expect both dependent variables will similarly signal citizens' resentment towards the hegemonic party.

Figures 4 and 5 demonstrate how Taiwanese ethnicity, conditional on local ethnic democracy, influences the occurrence of non-responses as well as the voters' perception of the quality of elections (the full regression tables are available in the Online Appendix). First, while Taiwanese ethnicity is positively associated with non-response in the authoritarian election (the 1983 election), we also find that Taiwanese voters are more likely than their Mainlander peers to consider that elections might be rigged. Next, we also find a similar pattern that shows how local ethnic demography can moderate the anti-incumbent effect of Taiwanese ethnicity in the 1983 election. As the proportion of the Taiwanese group increases in the townships, Taiwanese voters are less likely to provide non-responses and are more likely to consider elections to be free and fair.


Figure 4: Non-responses: 1983 Survey and 1992 Survey. Error bars show the 95\% confidence intervals. 


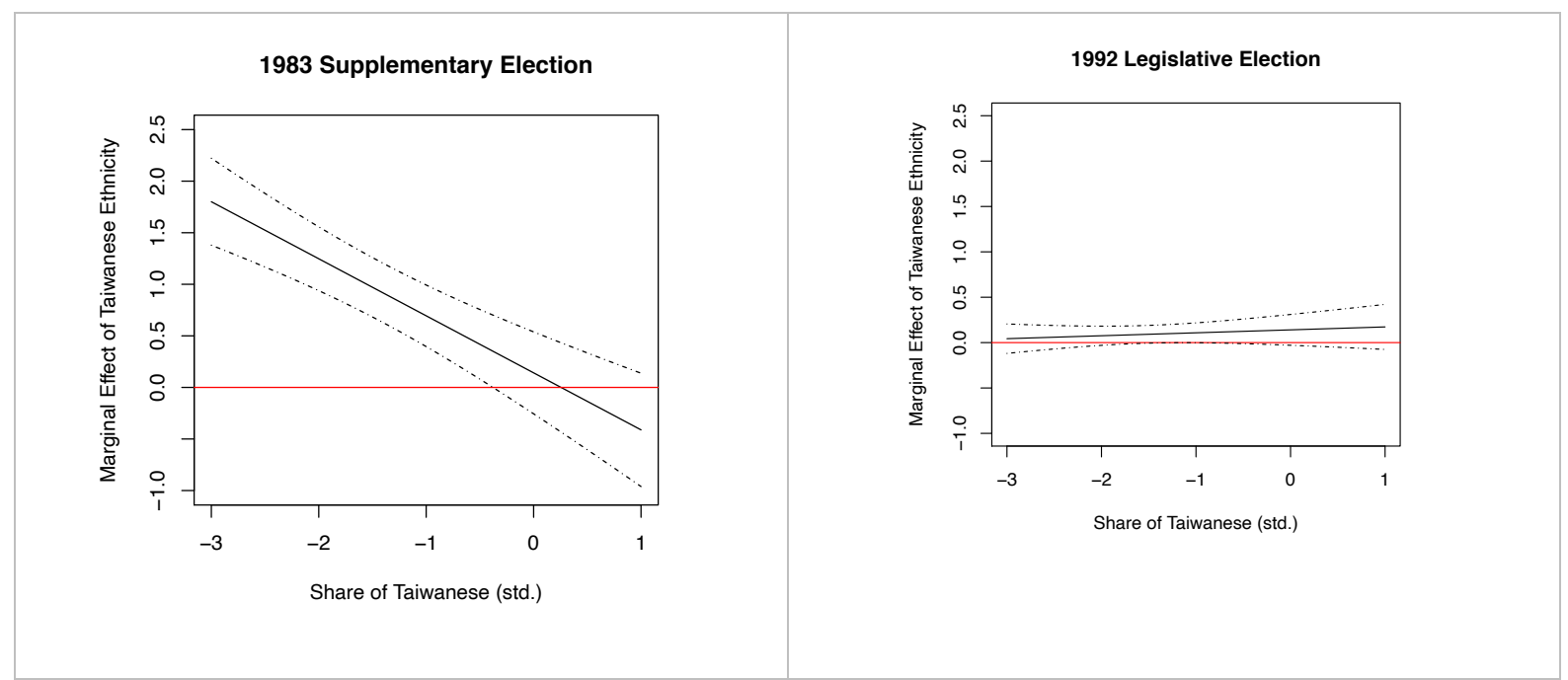

Figure 5: Perceived electoral fraud: 1983 Survey and 1992 Survey. Error bars show the 95\% confidence intervals.

\section{Organized Opposition and Pro-defection Ethnic Voting}

We now test whether the presence of an organized opposition force indeed overcomes the constraints of ethnicity as an informal driver for collective action. Full regression tables are available in the Online Appendix. We have retrieved historical records that document the date on which the DPP established its local branches across different municipalities and counties. As indicated by the DPP, it requires at least 200 members to build a local branch at the county level (Huang, 1992). These local branches play a critical role in recruiting members for the party and organizing mass rallies during the elections (Fan, 1994). We use the timing of each local office's establishment to indicate the variation in the strength of the DPP's grassroots party machine. ${ }^{17}$

We divide respondents by county -- counties in which a DDP local office was established within a year following its formal creation in 1986, or by the official lifting of martial law in 1987, and those that had to wait more than one year to achieve such a position. We have decided to use the end of martial law as the cut-off, as it would require extra effort at the grassroots level 
when the official ban on the formation of new parties remained in place. If the DPP fosters antiincumbent ethnic voting among Taiwanese voters, we should only see the decline in the prodefection effect of Taiwanese ethnicity in counties where it took the DPP additional time to build its grassroots presence.

The results in Figure 6 are consistent with our expectations. In counties where the DPP was able to build regular bases during martial law, Share of Taiwanese does not undermine the pro-defection effect of Taiwanese (top panel of Figure 6). In counties where local branches appeared late (bottom panel of Figure 6), the share of the Taiwanese group in the township still hindered the anti-incumbent effect of Taiwanese ethnicity, as the coefficients of the interaction term are negative and significant. Compared with the results in Table 1, we observe a larger negative interaction for counties where the DPP appeared to struggle to build a formal base. In other words, the absence of local opposition organizations makes it more difficult for Taiwanese ethnicity to facilitate ethnic voting against the hegemonic party.

Nonetheless, the top panel of Figure 6 also suggests that the grassroots party organizations were unable to mobilize the Taiwanese voters in the early 1990s, as we would observe a significant, positive interaction in that case. This finding may be unsurprising because, as indicated by Huang (1992), the KMT regime remained dominant in the 1990s, and it was not until 2000 that Taiwan saw the first switch of the ruling party. However, considering that the DPP started grassroots party building in the urban areas, the opposition party was still moderately successful in terms of countering the challenge of ethnic voting in a large group. 


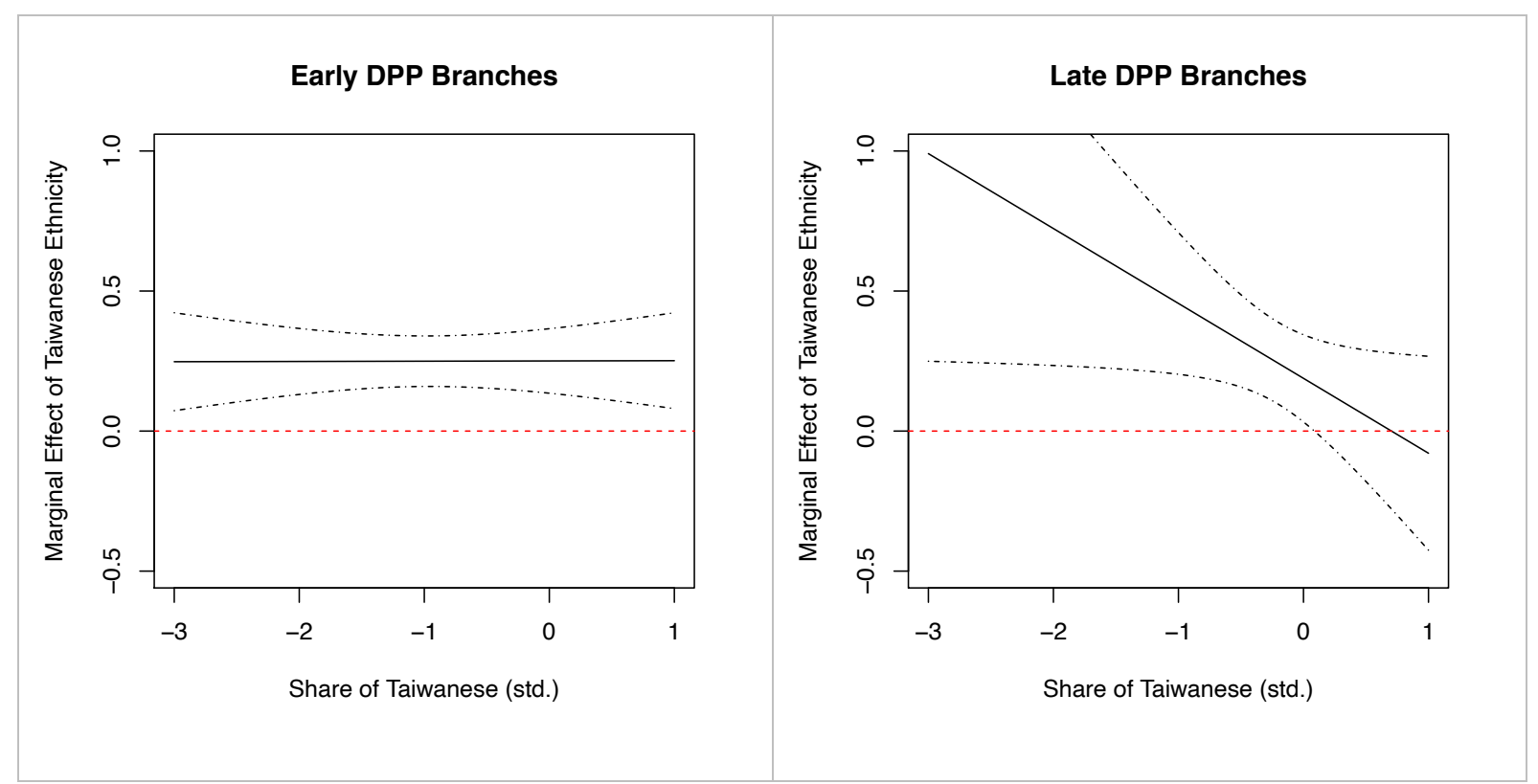

Figure 6: DPP local branches and pro-defection ethnic voting: Branches Before and After Martial Law.

Conversely, we consider the effect of Taiwanese ethnicity conditional on the hegemonic party's local presence. We have retrieved the results of the 1990 township elections and divide up the respondents based on whether the KMT was able to garner more than 50 per cent of the popular votes. As shown by Figure 7, we find that Share of Taiwanese was only negatively associated with Taiwanese ethnicity's anti-incumbent effect when the KMT was politically dominant at the grassroots level. 
KMT More Than $50 \%$

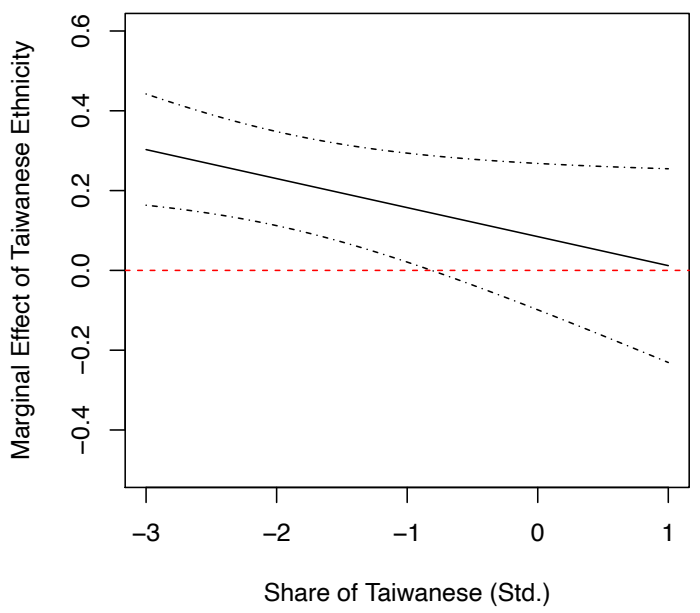

KMT Less Than $50 \%$

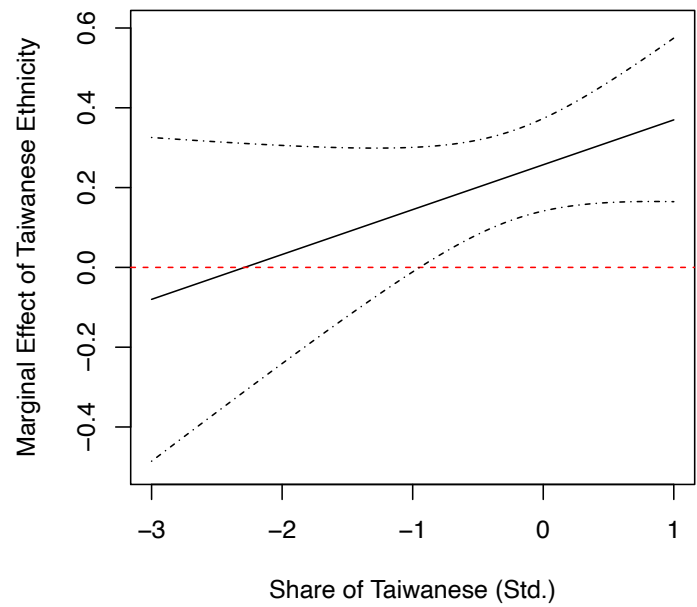

Figure 7: KMT's vote share and pro-defection ethnic voting: $\geq 50 \%$ and $<50 \%$.

\section{Conclusion}

Drawing on unique historical surveys in Taiwan, we show that subordinate or politically dominated ethnicity can drive voter defection against the incumbent autocrat. While shared ethnic ties indeed can induce coordination among voters and the opposition, the effectiveness of ethnicity for political mobilization remains constrained in the absence of organized opposition forces in electoral authoritarian regimes. Together, our findings suggest that the visibility of group differences alone does not sustain ethnic voting, which will require some organizational base. Compared with democracies, ethnically dominated groups are more likely to face more constraints in building such a base. In the context of Taiwan, the DPP's founding as a formal opposition party acted as the watershed -- the DPP consolidated the anti-autocrat effect of Taiwanese ethnicity such that Taiwanese voters' defection from the KMT is no longer constrained by its relative size in the townships. 
Our findings have implications for other ethnically diverse electoral autocracies. For regimes that have also undergone democratic transitions, such as the former Soviet Union and Indonesia, one can study whether the same conditional pro-defection effect of shared ethnicity was also present. As in the case of Sub-Saharan African countries, many of which similarly started multiparty elections in the early 1990s, one can also examine how the dictator garners support. According to our theory, the relative size of the group that shares the same ethnicity with the dictator should not constrain his electoral support. Future research can also further explore pro-defection or anti-incumbent ethnic voting under different institutional settings - in our case, the opposition's chance of winning the election does not directly influence the political salience of ethnicity, as the threshold of winning is in general low under the SNTV system.

\section{Supplementary material}

To see the supplementary material for this article, please visit https://www.dropbox.com/s/7yhwb2fc2vxdt52/PROOFREAD\%20TaiwanAppendix_word\%20c yc.docx?dl=0.

\section{Acknowledgements}

Barbara Geddes, Jeff Lewis, John Fuh-sheng Hsieh, Karl Ho, Nick Lin, Yuree Noh, Steven Oliver, Jacob Ricks, Dan Slater, Chin-shou Wang, Ching-hsing Wang, Dennis Lu-chung Weng and Yao-yuan Yeh provided useful feedback during various stages of this project. We would also like to thank the participants of the Midwest Political Science Association Annual Conference, the American Association for Chinese Studies Annual Conference, the Western Political Science Association Annual Conference, and the IR/CP Workshop at the University of 
South Carolina, as well as three anonymous reviewers, for their insightful comments. The East Asian Library at Stanford University provided generous financial support. The Social Sciences Information Center and the Election Study Center at National Chengchi University and the Survey Research Data Archive (SRDA) at Academia Sinica provided the original data.

\section{Notes}

${ }^{1}$ The 28 February Incident in 1947 was the first violent confrontation between these two ethnic blocs (Lai, Myers and Wei, 1991).

${ }^{2}$ We do not expect to see that Taiwanese ethnicity can drive voter defection when the two ethnic blocs are about the same size in the local community since, as argued, the visibility of ethnic cleavages alone does not suffice to establish the political salience of ethnicity. We have also shown this empirically in one of our robustness tests by including a squared term of local ethnic demography.

${ }^{3}$ The KMT government held the first legislative election across the country in 1948. In total, 759 legislators were elected to represent different constituencies in both mainland China and Taiwan.

${ }^{4}$ During the 1960s, Albania and other countries began to question the KMT's presence as the legitimate Chinese government in the United Nations and proposed to replace it with the CCP in the Mainland. In 1971, the KMT government withdrew from the United Nations. Soon afterwards, many countries around the world, including the United States, cut their diplomatic ties with Chiang.

${ }^{5}$ The Mainlanders' share of the population had grown from about 10\% in the 1950 s to about $13 \%$ in 1990. According to the census data, the Mainlanders accounted for about 10\% (1956), 
$14.62 \%$ (1966), $14.57 \%$ (1980), and $13.31 \%$ (1990) of the total population in Taiwan, which includes Taiwan Province, Taipei Municipality and Kaohsiung Municipality, respectively. ${ }^{6} \mathrm{Wu}(2004)$ and many others suggest that the KMT decided to tolerate the DPP's presence partly due to pressure by the United States.

${ }^{7}$ In 1983, the supplementary election had six constituencies, each of which included more than one county in Taiwan. The 1992 election redrew the constituencies by county. ${ }^{8}$ One may also argue that Taipei Municipality, as the KMT's de facto capital in Taiwan, is more likely to see voters conceal their true voting preferences compared with their counterparts in other counties.

${ }^{9}$ During the Japanese colonial period, those migrating or travelling from the Mainland were considered foreign nationals and only accounted for a very small portion of the total population (less than 1\%) - these migrants were considered as Mainlanders after 1949 in the official statistics (Chen and Tuan, 1951).

${ }^{10}$ It is also important to point out that, with very few exceptions, the townships included in both surveys were mostly Hoklos, according to the Hakka Affairs Council. Excluding these Hakka townships does not change the results.

${ }^{11}$ The official records show that the candidates who contested as independents in the counties covered by the surveys were all Taiwanese politicians.

${ }^{12}$ The intermediate categories include 'literate but uneducated', 'primary school', 'junior high school', 'senior high school', 'vocational college' and 'university and above'. We excluded respondents who attend military schools and colleges because we are only interested in civilians' voting choices.

${ }^{13}$ One of the fixed effect coefficients will be the intercept, so we omit it in the table. 
${ }^{14}$ In the main analysis, we have decided to standardize the share of the Taiwanese group to address the issue of collinearity.

${ }^{15}$ During the martial law period, local factions, which provided the foundation of the KMT's clientelistic machine, engaged more in local elections than the supplementary elections at the national level.

${ }^{16}$ We also show the results based on the survey for the 1995 legislative election - the results remain consistent with our hypothesis.

${ }^{17}$ We have decided to focus on local offices at the county level because most of the DPP's partybuilding endeavours in the 1980 s took place in urban areas. 


\section{References}

Adida C, Gottlieb J, Kramon E and McClendon G (2017) Reducing or Reinforcing In-Group Preferences? An Experiment on Information and Ethnic Voting. Quarterly Journal of Political Science 12(4): 437-477. http://dx.doi.org/10.1561/100.00017018.

Aldrich JH (1995) Why Parties? Chicago: University of Chicago Press.

Beissinger MR (2002) Nationalist Mobilization and the Collapse of the Soviet State. New York: Cambridge University Press.

Birnir JK (2007) Ethnicity and Electoral Politics. New York: Cambridge University Press. Brancati D (2009) Peace by Design. New York: Oxford University Press.

Cederman L-E, Wimmer A and Min B (2010) Why Do Ethnic Groups Rebel? New Data and Analysis. World Politics 62(1): 87-119. https://doi.org/10.1017/S0043887109990219.

Cederman L-E, Weidmann NB and Gleditsch KS (2011) Horizontal Inequalities and Ethnonationalist Civil War: A Global Comparison. American Political Science Review 105(3): 478-495. https://doi.org/10.1017/S0003055411000207.

Chandra K (2004) Why Ethnic Parties Succeed. Cambridge: Cambridge University Press.

Chang C-H and Huang C (2011) Party Competition and the Connection between the Taiwanese Ethnic Identity and National Identity. Taiwanese Political Science Review 15(1): 3-71. In Chinese. http://dx.doi.org/10.6683\%2fTPSR.201106.15(1).3-71.

Chao Y-M (1996) The Relationship between Local Factions and Political Democratization on Taiwan. Taiwanese Journal of Political Science 7: 39-56. In Chinese.

Chen C-S and Tuan C-H (1951) Population of Taiwan. Bank of Taiwan Quarterly 4(1): 39-120. In Chinese. 
Cheng S-F (2009) Ethnicity, Identity, and Vote Choice in Taiwan. Electoral Studies 16(2): 2349. In Chinese. http://dx.doi.org/10.6612\%2ftjes.2009.16.02.23-49.

Cheng T-J (1989) Democratizing the Quasi-Leninist Regime in Taiwan. World Politics 41(4): 471-499. https://doi.org/10.2307/2010527.

Cohen MJ (2018) Protesting via the Null Ballot: An Assessment of the Decision to Cast an Invalid Vote in Latin America. Political Behavior 40: 395-414. https://doi.org/10.1007/s11109-017-9405-9.

Copper JF and Chen GP (1984) Taiwan's Elections: Political Development and Democratization in the Republic of China. Occasional Papers in Contemporary Asian Studies 5. Baltimore: School of Law, University of Maryland.

Cox G (1999) Electoral Rules and Electoral Coordination. Annual Review of Political Science 2: 145-161. https://doi.org/10.1146/annurev.polisci.2.1.145.

Cox G and McCubbins M (1993) Legislative Leviathan. Berkeley: University of California Press.

Eifert B, Miguel E and Posner DN (2010) Political Competition and Ethnic Identification in Africa. American Journal of Political Science 54(2): 494-510. https://doi.org/10.1111/j.15405907.2010.00443.x.

Fan Y (1994) Local Headquarters and Mobilization Networks of the Democratic Progressive Party. Master's thesis. National Taiwan University. In Chinese.

Ferree KE (2006) Explaining South Africa's Racial Census. Journal of Politics 68(4): 803-815. https://doi.org/10.1111/j.1468-2508.2006.00471.x. 
Finkel E (2015) The Phoenix Effect of State Repression: Jewish Resistance During the Holocaust. American Political Science Review 109(2): 339-353. https://doi.org/10.1017/S000305541500009X.

Gandhi J and Ellen L-O (2009) Elections under Authoritarianism. Annual Review of Political Science 12: 403-422. https://doi.org/10.1146/annurev.polisci.11.060106.095434.

Gates H (1981) Ethnicity and Social Class. In The Anthropology of Taiwanese Society, eds. Emily Martin Ahern and Hill Gates. Palo Alto: Stanford University Press.

Geddes B and Zaller J (1989) Sources of Popular Support for Authoritarian Regimes. American Journal of Political Science 33(2): 319-347. https://doi.org/10.2307/2111150.

Hale HE (2008) The Foundations of Ethnic Politics. Cambridge: Cambridge University Press. Horowitz J and Long J (2016) Strategic Voting, Information, and Ethnicity in Emerging Democracies: Evidence from Kenya. Electoral Studies 44: 351-361. https://doi.org/10.1016/j.electstud.2016.08.009.

Hsieh, JF-S (2003) Democratizing China. Journal of Asian and African Studies 38(4-5): 377391. https://doi.org/10.1177\%2F002190960303800404.

Huber JD and Suryanarayankas P (2016) Ethnic Inequality and the Ethnification of Political Parties. World Politics 68(1): 149-188. https://doi.org/10.1017/S0043887115000349.

Huang T-F (1992) Democratic Progressive Party and Political Democratization in Taiwan. Taipei: Shihying. In Chinese.

Kasara K (2017) Does Local Ethnic Segregation Lead to Violence? Evidence from Kenya. Quarterly Journal of Political Science 11(4): 471-501. http://dx.doi.org/10.1561/100.00014115. 
Lai T-H, Myers R and Wei W (1991) A Tragic Beginning: The Taiwan Uprising of February 28, 1947. Palo Alto: Stanford University Press.

Lijphart A (1999) Patterns of Democracy. New Haven: Yale University Press.

Magaloni B (2006) Voting for Autocracy. New York: Cambridge University Press.

Olson M (1965) The Logic of Collective Action. Cambridge, MA: Harvard University Press.

Panebianco A (1988) Political Parties: Organization and Power. New York: Cambridge University Press.

Posner DN (2004) The Political Salience of Cultural Difference: Why Chewas and Tumbukas Are Allies in Zambia and Adversaries in Malawi. American Political Science Review 98(4): 529-545. https://doi.org/10.1017/S0003055404041334.

Posner DN (2017) When and Why Do Some Social Cleavages Become Politically Salient Rather Than Others? Ethnic and Racial Studies 40(12): 2001-2019. https://doi.org/10.1080/01419870.2017.1277033.

Roeder PG (1991) Soviet Federalism and Ethnic Mobilization. World Politics 43(2): 196-332. https://doi.org/10.2307/2010471.

Sheng S-Y (1986) Electoral Competition between KMT and non-KMT Association. Taipei: Laureate. In Chinese.

Shi T (1999) Voting and Nonvoting in China: Voting Behavior in Plebiscitary and LimitedChoice Elections. Journal of Politics 61(4): 1115-1139. https://doi.org/10.2307/2647556. Wang C-S. 1997. Building and Operating KMT Candidates' Vote Buying Machine: A Case Study of 1993 Fong-Mong County Mayor Election. Taiwanese Political Science Review 2(1): 3-61. In Chinese. 
Wang C-S and Kurzman C (2007) Dilemmas of Electoral Clientelism: Taiwan, 1993. International Political Science Review 28(2): 225-245. https://doi.org/10.1177\%2F0192512107075408.

Wang F-C (2005) From Chinese Original Domicile to Taiwanese Ethnicity: An Analysis of Census Category Transformation in Taiwan. Taiwanese Sociology 9: 59-117. In Chinese. http://dx.doi.org/10.6676\%2fTS.2005.9.59.

Wang F-C (2008) The Role of Ethnic Politics Issues in Taiwan's Democratic Transition. Taiwan Journal of Democracy 5(2): 89-140. In Chinese.

Wu C-L and Hsiao C-T (2006) Empowerment Theory and Ethnic Politics in Taiwan. Issues \& Studies 42(1): 103-136. http://dx.doi.org/10.7033\%2fISE.200603_42(1).0004.

Wu N-T (1987) The Politics of a Regime Patronage System: Mobilization and Control within an Authoritarian Regime. PhD dissertaion. University of Chicago.

Wu N-T (2004) Reformer or Dictator? Reassessing the Role of Chiang Ching-Guo in the Democratic Transition. In Democratic Development in Taiwan in the 20th Century, ed. ChienKuo Hu. Taipei: Academia Historical. In Chinese.

Yang DD (2011) Class, Ethnicity, and the Mass Politics of Taiwan's Democratic Transition. World Politics 59(4): 503-538. https://doi.org/10.1353/wp.2008.0006. 